\title{
PROCESSOS DE INCLUSÃO/EXCLUSÃO SOCIAL DE PESSOAS COM DEFICIÊNCIA NO MERCADO DE TRABALHO: RELAÇÃO ENTRE EMPREGABILIDADE E FORMAÇÃO PROFISSIONAL
}

\author{
Amanda Carlou ${ }^{1}$ \\ Annie Gomes Redig ${ }^{2}$
}

\section{RESUMO}

Este artigo resulta de uma pesquisa sobre a empregabilidade de pessoas com deficiência e a relação entre a formação profissional e o mercado de trabalho no contexto atual da sociedade brasileira, baseada nos paradigmas da inclusão. As reflexões sobre os dados estatísticos relativos à ocupação desses indivíduos bem como os processos educacionais em que estão inseridos nos permitem entender o panorama dos processos de inclusão/exclusão social de tais sujeitos. O objetivo da discussão tratada neste trabalho é compreender os impactos da formação profissional para o desenvolvimento da vida autônoma e produtiva de pessoas com deficiência. O artigo evidencia que persistem os desafios de mudanças na organização das práticas formativas para esse grupo, destacando conceitos necessários para a construção de caminhos possíveis na busca de uma maior participação social.

Palavras-Chave: Exclusão. Formação profissional. Inclusão. Mercado de trabalho. Pessoa com deficiência.

\footnotetext{
${ }^{1}$ Mestranda do Programa de Pós-Graduação em Educação (PROPEd/UERJ). Pedagoga responsável pelos Núcleos de Apoio às Pessoas com Necessidades Específicas (NAPNE) do Instituto Federal de Educação, Ciência e Tecnologia do Rio de Janeiro (IFRJ), professora substituta da Faculdade de Educação da UERJ.

2 Doutoranda do Programa de Pós-Graduação em Educação (PROPEd/UERJ). Professora de atendimento educacional especializado da rede pública do município do Rio de Janeiro, professora substituta da Faculdade de Educação da UERJ e tutora à distância do CEDERJ/UERJ.
}

|Fed. Nac. das Apaes - Fenapaes $\mid$ Brasília/DF | v.1 | nº1 | P. 53 - 69 |ago/dez .2013|ISSN 2237-4329 


\title{
PROCESSOS DE INCLUSÃO/EXCLUSÃO SOCIAL DE PESSOAS COM DEFICIÊNCIA NO MERCADO DE TRABALHO: RELAÇÃO ENTRE EMPREGABILIDADE E FORMAÇÃO PROFISSIONAL
}

\begin{abstract}
This article results of a research about the employability of people with deficiency and the relation between professional development and labor market in the present context of the Brazilian society based on the paradigms of inclusion. The reflections about the statistical data related to the occupation of these individuals as well as the educational processes in which they are inserted allow us to understand the panorama of the processes of social inclusion/exclusion of those subjects. The objective of this work is to understand the impacts of professional development for the productive and autonomous life of people with deficiency. The article shows that the challenges of organization changes in the formative practices for this group still persist, emphasizing necessary concepts for the construction of possible ways in the search of a broader social participation.
\end{abstract}

Keywords: Exclusion. Professional development. Inclusion. Labor market. Person with deficiency. 


\section{INTRODUÇÃO}

Este texto tem como objetivo discutir sobre os processos de inclusão/exclusão social de pessoas com deficiência no mercado de trabalho, com base na análise do conceito de exclusão, a partir das reflexões de Jodelet (2008). Para essa autora,

[...] há pelo menos um nível onde uma abordagem única da exclusão pode fazer sentido: o nível das interações entre pessoas e entre grupos, que delas são agentes ou vítimas. Este nível é próprio da Psicologia Social. (p. 53)

Nessa perspectiva, os membros são considerados equivalentes, em razão de características, intenções e ações comuns, sendo assim é possível apontar dois sentidos para a categorização psicossocial. O primeiro deles refere-se à classificação em uma divisão social, isto é, colocamos as pessoas em uma determinada categoria, como por exemplo: mulheres, homens, velhos, crianças, jovens etc. $O$ segundo diz respeito à atribuição de uma característica a alguém, geralmente aqueles que, de imediato, apresentam alguma propriedade física, afetiva ou social com as quais não se identificam, não gostariam de se identificar ou, ainda, não gostariam de ser identificados. É nesse contexto que se pode destacar o preconceito e o estereótipo. Segundo Glat (2008) o estranho, o diferente, tudo que foge aos padrões de normalidades estipulados pela sociedade é considerado como anormal, ameaçando a frágil estabilidade social. Nas palavras da autora, "a principal característica dos papéis sociais é que eles são aprendidos. Ninguém é geneticamente programado para representar certos tipos de papéis e não outros" (p. 30, grifo nosso).

Tomando como base esse princípio pretendemos discutir sobre a inclusão de pessoas com deficiência no mercado de trabalho, pois entendemos que a participação social e autônoma na sociedade por parte desses indivíduos é condição sine qua non para a superação do preconceito e o exercício da cidadania. 


\section{CONHECENDO OS DESAFIOS}

O processo de inclusão/exclusão tem sido amplamente discutido no âmbito acadêmico $^{3}$ e também no campo específico da Educação ${ }^{4}$. Historicamente, os processos de exclusão das pessoas com deficiência na sociedade têm dificultado o acesso desses indivíduos a bens essenciais como saúde, educação e trabalho. Alguns dos fatores atrelados a tal questão são baixa escolaridade, dificuldade de inserção social, pouca circulação e uso dos espaços públicos e comprometimento para desempenhar as atividades profissionais. Como afirmam Ferronatto, Wagner e Falkenback (2008), a lógica de exclusão social está atrelada a desinformação e preconceito e conduz a atitudes e práticas que dificultam ou impossibilitam as oportunidades e o acesso ao mercado de trabalho.

Nessa direção, faz-se necessária a discussão sobre a formação profissional de pessoas com deficiência e sua relação com o mercado de trabalho, buscando então relacionar os impactos que a qualificação/capacitação tem sobre as possibilidades de inclusão social desses sujeitos.

Sabe-se que a formação profissional de pessoas com deficiência tem sido um grande desafio no sentido de oportunizar a diminuição da exclusão social e promover a participação efetiva dessas pessoas na sociedade através do exercício pleno da cidadania. Nessa perspectiva, compreendemos que através do acesso à educação e ao desenvolvimento da aprendizagem é possível propiciar aos alunos com deficiência uma vida autônoma através da elevação da escolaridade e da preparação para o trabalho. Entendendo que a formação profissional é uma etapa determinante na vida de qualquer pessoa, independentemente de sua condição, acreditamos que, no contexto de uma sociedade inclusiva, muitas são as possibilidades de inserção social desses sujeitos. Consoante a isso, Dejours (2004, p. 30) nos diz:

O trabalho sempre coloca à prova a subjetividade, da qual esta última sai acrescentada, enaltecida ou, ao contrário, diminuída, mortificada. Trabalhar constitui, para a subjetividade, uma provação que a transforma. Trabalhar não é somente produzir; é, também, transformar

\footnotetext{
${ }^{3}$ Como em Wanderley (2008), Jodelet (2008), Martins (1997), entre outros.

${ }^{4}$ Os trabalhos de Mattos (2002), Dubet (2003) e Bueno (2005) são exemplos.
}

|Fed. Nac. das Apaes - Fenapaes $\mid$ Brasília/DF | v.1 | nº | P. 53 - 69 |ago/dez .2013|ISSN 2237-4329| 


\section{Apøe Ciênciø Artigo}

a si mesmo e, no melhor dos casos, é uma ocasião oferecida à subjetividade para se testar, até mesmo para se realizar.

Porém, estudos na área ${ }^{5}$ evidenciam as dificuldades vivenciadas pelas redes para implementar propostas educacionais inclusivas. Essas pesquisas apontam também que as condições necessárias para a concretização da política de inclusão de alunos com necessidades educacionais ainda não foram asseguradas nas escolas públicas brasileiras. É importante ressaltar que a política de inclusão deve contemplar todas as esferas do desenvolvimento, não somente a educação, mas também a vida familiar, saúde, lazer, trabalho, etc. Porém, a escola, na maioria dos casos, acaba se tornando um dos únicos ambientes que esse indivíduo frequenta e que proporcione momentos de interação, troca de experiência e crescimento pessoal. Por isso, a escola precisa ser um lócus aberto à diversidade, de construção de conhecimento acadêmico e para a vida, principalmente para os alunos com deficiência intelectual que possuem maiores comprometimentos, necessitando assim de suportes mais complexos e objetivos escolares diferenciados dos demais estudantes, mesmo os considerados da clientela tradicional da Educação Especial ${ }^{6}$. Para isso, as escolas regulares e as instituições especializadas devem desenvolver a autonomia e a independência de seus alunos, para a sua inclusão social (ROCHA et. al., 2011). Portanto, pensar na profissionalização e na formação para o mundo do trabalho de pessoas com deficiência é complexo, visto que ainda encontram-se dificuldades para o oferecimento de um ensino básico que atenda as necessidades dessa população.

Mais de uma década após a promulgação da Declaração de Salamanca (UNESCO, 1994), percebe-se que as transformações ocorreram mais na esfera das políticas e da legislação do que em termos de ações efetivas, que garantam o processo ensino-aprendizagem de alunos com deficiências incluídos no ensino comum, para além de sua simples matrícula. O percurso de inclusão escolar e social deve iniciar na escola, de forma que oportunize momentos para o conhecimento de possibilidades de trabalho, na aquisição de habilidades laborais e sociais. De acordo com o Decreto 7611 (BRASIL, 2011), deve haver a adoção de estratégias de apoio individualizado para o desenvolvimento acadêmico e social, seguindo a meta de inclusão plena. Nessa direção, a Declaração de Salamanca (UNESCO, 1994) aponta

\footnotetext{
${ }^{5}$ Ver trabalhos de Redig (2010), Glat (2008), Pletsch (2009), Fontes (2007), entre outros.

${ }^{6}$ Os alunos considerados da clientela tradicional da Educação Especial são os que apresentam deficiência física, sensoriais, intelectuais, com transtornos globais do desenvolvimento ou altas habilidades/superdotação.
}

|Fed. Nac. das Apaes - Fenapaes $\mid$ Brasília/DF | v.1 | nº | P. 53 - 69 ago/dez .2013| ISSN 2237-4329| 


\section{Apøe Ciênci@ Artigo}

\section{apaeciencia.org.br/revista}

que o currículo para jovens e adultos com deficiências precisa incluir programas de transição, treinamento vocacional, com oficinas de trabalho, serviços e agências. Para autores como Perosa (1979), Manzini (1989), Goyos (1995), Tanaka (1996) e Nunes et al. (1998), existem falhas no processo de formação e qualificação profissional de pessoas com deficiência no Brasil. As escolas não promovem oportunidades para a preparação e/ou capacitação dos jovens e adultos ditos "normais", quiçá para os com deficiência intelectual, por isso é necessário atentarmos para a questão da empregabilidade desses sujeitos, no que diz respeito a sua capacitação.

Essa formação tem sido desenvolvida, em muitos casos, através de programas com oficinas pedagógicas ou protegidas ${ }^{7}$ de instituições de ensino especial. Entretanto, existem críticas em relação aos procedimentos que esses programas utilizam, por considerarem que as atividades comumente ensinadas, como artesanato, tapeçaria e marcenaria, são selecionadas mais em função dos recursos materiais disponíveis e da tradição institucional do que da demanda do mercado, pouco contribuindo para efetivamente qualificar essa população.

Sassaki (ano apud SANTOS; COSTA, 2011, p. 2720) lembra que "as escolas especiais, centros de habilitação, oficinas protegidas e centros de profissionalização colaboraram com a colocação desses profissionais no trabalho". Porém, as oficinas pedagógicas não cumpriram com a função de "tentar imitar" uma empresa, pois os alunos desenvolviam atividades laborais sem a remuneração no final. Sendo assim, eles não eram treinados para compreender as regras do mercado capitalista. Entretanto, o fato de esses sujeitos estarem em contato com esse tipo de atividade traz benefícios na medida em que os ajuda a desenvolver autonomia, mas de forma descontextualizada da competitividade mercadológica. Os escassos estudos sobre esse tipo de atendimento apontam para dificuldades e críticas na sua realização, como observa Silva (2006): isolamento do sujeito do mundo externo, subcontratos desfavoráveis para os jovens e adultos trabalhadores, crise financeira da instituição e do país, incompatibilidade das atividades de ensino com as necessidades do mundo do trabalho, entre outras. Fogli (2010) sinaliza que essas iniciativas acontecem em instituições de ensino especial e por isso geralmente são desenvolvidas atividades de

\footnotetext{
7 "Oficina pedagógica - Tem caráter educativo e sem fins lucrativos, ocorre em um ambiente supervisionado, onde o objetivo é desenvolver hábitos de independência pessoal e social relativos ao trabalho competitivo; Oficina protegida ou abrigada - É um tipo de oficina, também sem fins lucrativos e desenvolvida em ambiente supervisionado, onde os alunos são preparados para o início de uma função produtiva e renumerada, ajudando-os a manter os hábitos e atitudes adquiridos nos estágios anteriores". (MASCARO, 2012, p. 46)
}

|Fed. Nac. das Apaes - Fenapaes $\mid$ Brasília/DF | v.1 | nº | P. 53 - 69 |ago/dez .2013|ISSN 2237-4329| 


\section{Apøe Ciênciø Artigo}

\section{apaeciencia.org.br/revista}

artesanato, tapeçaria, marcenaria, etc. Vale refletir sobre a pertinência desse tipo de curso em relação às reais demandas do mercado de trabalho. Contudo, deve-se levar em conta o objetivo da atividade proposta: profissionalizar ou apenas "dar uma ocupação" ao sujeito.

Corroborando com essa discussão, Silva (2006) acrescenta que o debate da equidade nos leva a refletir que, se todos tiverem as mesmas oportunidades de acesso, o fracasso ou o sucesso, seja na escola ou no trabalho, serão de responsabilidade do próprio indivíduo. Entretanto, vale lembrar que esses sujeitos possuem limitações, ocasionadas pela sua deficiência, que os impedem de exercer certas funções, tendo como consequência um resultado negativo ou positivo. Dessa forma, podemos caminhar para uma exclusão dentro da proposta da inclusão, na qual exige-se da pessoa com deficiência que realize as mesmas funções que os demais.

Não basta a criação de leis que estimulem a participação desse público em cursos profissionalizantes ou mesmo que demandem a contratação de pessoas com deficiência. São necessárias a flexibilização e a adaptação das leis trabalhistas, a fim de garantir a inclusão laboral desses sujeitos. Isso significa que, independentemente da política de cotas, esses sujeitos continuam excluídos do mercado de trabalho, principalmente por serem contratados apenas para o cumprimento da lei, e não com o objetivo de produtividade. Segundo Araújo e Schmidt (2006), pelo fato de essas pessoas terem sido marginalizadas e excluídas das oportunidades do convívio em sociedade, elas foram privadas "de uma série de bens culturais e intelectuais, prejudicando-as no seu processo de inserção social e trabalhista” (p. 242).

\section{CENÁRIO ATUAL E CAMINHOS POSSÍVEIS}

As mudanças sociais ocorridas nas últimas décadas têm promovido maiores possibilidades de inclusão de pessoas com deficiência no mercado de trabalho e refletem um novo paradigma sobre o modelo de sociedade. Essas transformações podem ser identificadas pela ampliação do debate acerca dos direitos desses indivíduos e pela criação de legislações específicas para inclusão social e no mercado de trabalho.

De acordo com a Declaração Mundial de Educação para Todos (UNESCO, 1990), a sociedade inclusiva se baseia no respeito aos direitos humanos, à liberdade, à diversidade, à justiça social de grupos vulneráveis e marginalizados em busca da participação democrática e do exercício dos direitos. Desse modo, torna-se fundamental a promoção de equiparação de

|Fed. Nac. das Apaes - Fenapaes $\mid$ Brasília/DF | v.1 | n¹ | P. 53 - 69 |ago/dez .2013| ISSN 2237-4329| 


\section{Apøe Ciênci@ Artigo}

oportunidades e a incorporação de medidas que favoreçam a participação das pessoas com deficiência em todas as esferas da vida.

Percebemos um movimento atual em que as políticas públicas têm dado especial atenção às propostas que buscam promover a participação e a inclusão dos indivíduos com deficiência no mercado de trabalho, considerando que o trabalho tem papel relevante na vida de todos os indivíduos. O trabalho é apontado por muitos autores ${ }^{8}$ como atividade fundamental para a realização pessoal, desenvolvimento da autoestima, interação social, sentimento de pertença e capacidade, bem como construção de identidade e autonomia.

De acordo com os dados da Relação Anual de Informações Sociais (RAIS) de 2007, do Ministério do Trabalho e do Emprego (MTE), referente à inclusão das pessoas com deficiência no mercado de trabalho, constata-se que dos 37,6 milhões de postos de trabalho apenas 348,8 mil (1\%) são ocupados por pessoas com deficiência. Nos últimos anos ganharam posição de destaque no cenário nacional as medidas que visam à inclusão desses indivíduos no mercado formal e informal, decorrentes da política de cotas da Lei 8.213/91 (BRASIL, 1991), a qual surgiu como um facilitador para inserção de pessoas com deficiência no setor privado. Essa lei prevê que as empresas que possuem 100 ou mais empregados são obrigadas a preencher de $2 \%$ a $5 \%$ dos seus cargos com beneficiários reabilitados ou com pessoas com deficiência ${ }^{9}$.

De acordo com Mendonça (2007), a legislação brasileira é considerada uma das mais avançadas em relação às questões sobre inclusão das pessoas com deficiência no mercado de trabalho e possui consolidada base constitucional e conjunto de princípios legais que asseguram uma vida digna a essas pessoas. O que se percebe, no entanto, é que na prática tal lei ainda se encontra muito frágil, indicando ser imprescindível uma maior fiscalização do cumprimento das leis bem como uma melhor qualificação das ações referentes à profissionalização da população com deficiência para o mercado de trabalho, visando promover e garantir a sua participação (TOLDRÁ; DE MARQUE; BRUNELLO, 2010).

A inserção de pessoas com deficiência no contexto do mercado de trabalho é um tema que vem fazendo parte das discussões na esfera da Educação Especial há tempos. Entretanto, a preocupação com tal questão começou a se estender para o âmbito empresarial somente a

\footnotetext{
${ }^{8}$ Ver estudos de Giordano (2000), Lancillotti (2003), Netto (2003), Saint-Jean (2003), Cezar (2012), entre outros.

${ }^{9} \mathrm{O}$ percentual a ser aplicado varia de acordo com o número total de empregados, da seguinte forma: de 100 a 200 empregados, $2 \%$; de 201 a 500 empregados, $3 \%$; de 501 a 1000 empregados, $4 \%$; de 1001 em diante, $5 \%$.
}

\begin{tabular}{|l|l|l|l|l|l|} 
Fed. Nac. das Apaes - Fenapaes & Brasília/DF & v.1 & n $^{\circ} 1$ & P. 53 - 69 & ago/dez .2013| ISSN 2237-4329
\end{tabular} 


\section{Apøe Ciênciø Artigo}

\section{apaeciencia.org.br/revista}

partir da aprovação de leis específicas, como a já citada Lei 8.213/91 (BRASIL, 1991), que procuram assegurar esse direito.

Porém, mesmo com tal garantia prevista em lei, ainda assim nota-se que as oportunidades de acesso ao mercado de trabalho para esse grupo específico vêm acontecendo de forma bastante lenta. A inserção das pessoas com deficiência no mercado de trabalho é impulsionada, muitas vezes, devido à fisscalização rigorosa realizada pelo Ministério Público do Trabalho (MPT), mediante punições às empresas que não cumprem as leis (MANZINI; TANAKA, 2005).

A partir da exigência imposta pela lei começou a haver uma maior oferta de vagas de emprego para pessoas com deficiência. No entanto, apesar de essas leis terem funcionado como uma válvula impulsionadora para o oferecimento de vagas nas empresas, o número de pessoas com deficiência que está efetivamente no mercado de trabalho ainda está muito distante do ideal. De acordo com Neri, Carvalho e Costilla (2002), os dados da Relação Anual de Informações (RAIS) revelam que, dos 26 milhões de trabalhadores formais ativos, apenas 537 mil, aproximadamente, eram de pessoas com deficiência; o que representa apenas $2,05 \%$ desse total.

Sabemos que o nosso país tem um grupo significativo de pessoas desempregadas ${ }^{10}$, por isso a grande competitividade para conseguir um espaço no mercado de trabalho. Especificamente sobre as pessoas com deficiência, a falta de informação sobre a deficiência associada à possível crença de que o indivíduo não irá corresponder à carga de trabalho imposta pelo mercado pode, por fim, gerar antagonismos quanto à colocação desses indivíduos nos postos de trabalhos das empresas. Para Ferreira (1998), a desinformação pode produzir desconhecimento sobre as reais potencialidades, necessidades, expectativas e sentimentos desses sujeitos.

Em estudo realizado por Manzini e Tanaka (2005), foram coletados dados de seis pessoas responsáveis pelo setor de recursos humanos de seis empresas que empregavam pessoas com deficiência e possuíam mais de 100 funcionários no seu quadro de pessoal. Alguns dos resultados dessa pesquisa apontam a formação profissional como barreira, pois muitos desses sujeitos não apresentam nível de escolaridade de acordo com as necessidades do mercado nem formação profissional específica para o exercício de algumas funções. Os

\footnotetext{
${ }^{10}$ De acordo com o censo 2010 o Brasil tem 8 milhões de pessoas desempregadas totalizando $6,7 \%$ da população.
}

|Fed. Nac. das Apaes - Fenapaes $\mid$ Brasília/DF | v.1 | nº | P. 53 - 69 |ago/dez .2013| ISSN 2237-4329| 


\section{Apøe Ciênciø Artigo}

\section{apaeciencia.org.br/revista}

autores apontam ainda como possível solução para essa questão a capacitação profissional voltada para o mercado de trabalho em igualdade de condições das demais pessoas.

Dados recentes de pesquisa realizada pelo Instituto Brasileiro de Geografia e Estatística (IBGE), através do censo demográfico de 2010, confirmam o quadro precário em relação a escolaridade e empregabilidade de pessoas com deficiência. O gráfico a seguir demonstra que o grupo de pessoas com deficiência, em comparação com as demais pessoas, apresenta um índice de escolaridade muito baixo, em que muitas não têm qualquer tipo de instrução ou apenas o fundamental incompleto.

Gráficos 1 e 2 - Distribuição percentual da população com deficiência e seu nível de instrução.

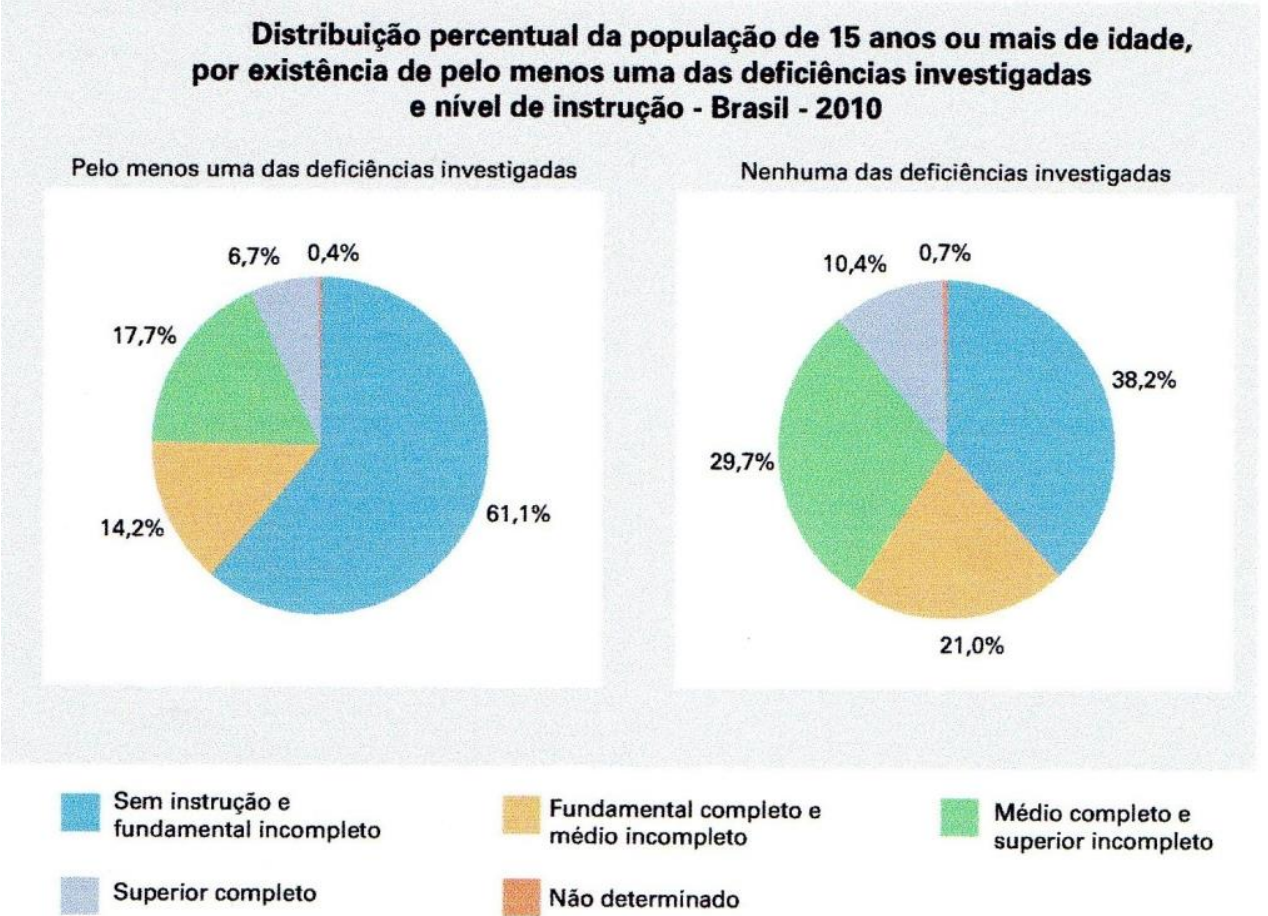

Fonte: Censo Demográfico 2010 (IBGE).

Os dados mostram que enquanto $61,1 \%$ da população de 15 anos ou mais de idade com deficiência não tinha instrução ou possuía apenas o fundamental incompleto, esse percentual era de $38,2 \%$ para pessoas de 15 ou mais anos que declararam não ter qualquer uma das deficiências investigadas, representando uma diferença de 22,9 pontos percentuais. Ou seja, no grupo de pessoas com deficiência a maioria percentual tem baixa escolaridade. 


\section{Apøe Ciênciø Artigo}

\section{apaeciencia.org.br/revista}

Ainda de acordo com o censo demográfico de 2010 observou-se que existem diferenças percentuais consideráveis em relação à empregabilidade de pessoas com deficiência de acordo com seu nível de instrução e em comparação com as demais pessoas. Os dados do IBGE registraram que 46,4\% da população com deficiência ganhava até 1 salário mínimo ou não tinha rendimento, uma diferença de mais de nove pontos percentuais em relação à população sem deficiência $(37,1 \%)$. A pesquisa mostrou que tais diferenças diminuem nas classes mais altas de rendimento, o que nos leva a inferir que quanto maior o nível de instrução, maiores serão as possibilidades de equiparação salarial e inserção no mercado de trabalho.

Considerando a profissionalização de pessoas com deficiência, esses dados têm sua dimensão ampliada, pois tais indivíduos ainda encontram grandes barreiras para o acesso a uma formação de qualidade, uma vez que, mesmo após a implementação das políticas de inclusão, a sua escolarização se dá em entidades filantrópicas específicas para o grupo. Mesmo aqueles que participam de um processo educacional inclusivo não estão ainda em igualdade de condições, posto que tais sistemas possuem práticas pedagógicas pouco eficazes para o desenvolvimento da aprendizagem. Consoante a isso, Fogli (2010, p. 65) observa:

[...] quando pensamos numa política de educação profissional que atenda às demandas inerentes à realidade das pessoas com deficiência, percebemos uma latente necessidade de ressignificação da organização do espaço-tempo escolar, de modo que este esteja ao alcance de todos.

É preciso registrar que algumas propostas vêm sendo elaboradas com o objetivo de contribuir para a superação desse quadro. Omote (2005) lembra que, assim como no mercado de trabalho, também a educação de crianças e jovens com deficiência vem sofrendo profundas mudanças nas últimas décadas. Como já mencionado, alguns procedimentos muito empregados durante um período de tempo acabaram contestados e abandonados ou transformados.

Essas mudanças vêm ocorrendo no sentido de ampliar progressivamente as alternativas educativas como também as oportunidades de participação nas diferentes atividades da sociedade. Um exemplo é a Política de Educação Especial na Perspectiva da Educação Inclusiva, elaborada pelo Ministério da Educação e implementada a partir de 2008 


\section{Apøe Ciênciø Artigo}

\section{apaeciencia.org.br/revista}

(BRASIL, 2008). Tal documento orienta os sistemas educacionais a se tornarem inclusivos e minimamente restritivos.

A partir dessa política houve um avanço expressivo em tal caminhada, pois com o paradigma da inclusão o foco não está apenas na pessoa com deficiência, mas também em todo o contexto. A política da Educação Inclusiva supõe uma profunda transformação da escola, tendo como princípio que esta é que deve se adaptar para garantir a participação de todos, e nesse sentido novas questões se apresentam e possibilidades se avistam. Em suma, podemos compreender, a partir do que foi exposto, que existe uma imperiosidade de se promover a inclusão social pela via da elevação da escolaridade e da formação profissional considerando que o homem catalisa a sua expressão transformadora e criadora pelo trabalho.

Dessa forma, apesar dos limites impostos pelo meio à inclusão, entendemos que é possível a construção de uma escola que considere cada indivíduo em sua singularidade e que tenha como pressuposto o trabalho como princípio educativo. A escola necessita também ter como objetivo o respeito à diversidade e à humanização nas relações ensino-aprendizagem, principalmente no que se refere à formação profissional de pessoas com deficiência.

\section{CONSIDERAÇÕES FINAIS}

Resgatando o conceito de trabalho como meio para a construção de autonomia e emancipação, compreendemos a formação profissional como uma possibilidade de humanização, porém ainda imersa num cenário de contradições. Com efeito, a análise dos dados sobre a escolarização de pessoas com deficiência e dos impactos sobre a inserção desse grupo no mercado de trabalho no contexto atual brasileiro nos permite concluir que as ações e propostas elaboradas ainda não são suficientes para garantir o processo sistemático de formação profissional numa perspectiva de educação que articule conhecimento e trabalho como condição de garantia de cidadania e vida autônoma produtiva.

A formação profissional se configura como uma possibilidade não somente formativa, mas humanizadora, escopo que enseja um movimento em prol da melhoria da qualidade dos processos educacionais, considerando que políticas, diretrizes e programas só se configuram em ferramentas de mudanças sociais a partir do processo de construção dialógica sobre seus princípios, seus fundamentos e sua relevância social. Esperamos, com as reflexões sobre os 


\section{Apøe Ciênciø Artigo}

\section{apaeciencia.org.br/revista}

dados apresentados neste trabalho, contribuir para os estudos sobre o papel da formação profissional para emancipação humana em uma perspectiva de sociedade inclusiva.

É importante que os sistemas educacionais voltados para a formação profissional estejam ancorados nos princípios de cidadania e democracia. Em se tratando da educação de pessoas com deficiência entendemos que os processos de escolarização e trabalho são fatores fundamentais para sua autonomia e vida produtiva, o que nos leva a registrar o papel singular das escolas para esse grupo. É nesse particular que residem as reais possibilidades de inclusão social dessas pessoas.

\section{REFERÊNCIAS}

BRASIL. Política Nacional de Educação Especial na Perspectiva da Educação Inclusiva. Disponível em: <http://portal.mec.gov.br/seesp/arquivos/pdf/politica.pdf〉. Acesso em: 18 dez. 2013.

Lei n. 8.213, de 24 de julho de 1991. Dispõe sobre o apoio às pessoas com deficiência e sua integração social, disciplina a atuação do Ministério Público, define critérios e dá outras providências. 1991.

Decreto n. 7.611, de 17 de novembro de 2011. Dispõe sobre a Educação Especial, o atendimento educacional especializado e dá outras providências. Disponível em: <http://www.planalto.gov.br/ccivil_03/_Ato2011-2014/2011/Decreto/D7611.htm>. Acesso em: 18 dez. 2013.

BUENO, J. G. S. Processos de inclusão/exclusão escolar, desigualdades sociais e deficiência. In: JESUS, D. M.; BAPTISTA, C. R.; VICTOR, S. L. (Orgs.) Pesquisa e Educação Especial: mapeando produções. Vitória: Edufes, 2005.

CEZAR, K. R. Pessoas com deficiência intelectual: inclusão trabalhista - lei de cotas. São Paulo: LTr, 2012.

DEJOURS, C. Subjetividade, trabalho e ação. Revista Produção, v. 14, n. 3, p. 27- 34, 2004.

DUBET, F. A escola e a exclusão. Cadernos de Pesquisa, n. 119, p. 29-45, jul. 2003.

FERREIRA, S. L. Aprendendo sobre a deficiência mental: um programa para crianças. São Paulo: Memnon, 1998.

FERRONATTO, B. C.; WAGNER, L. C.; FALKENBACK, A. P. Inclusão laboral da pessoa portadora de deficiência. Rev. Digital, Buenos Aires, v. 12, n. 117, 2008. Disponível em: $<$ http://www.efdeportes.com/efd117/inclusao-laboral-da-pessoa-portadora-dedeficiencia.htm>. Acesso em: 12 fev. 2013.

|Fed. Nac. das Apaes - Fenapaes $\mid$ Brasília/DF | v.1 | nº | P. 53 - 69 |ago/dez .2013| ISSN 2237-4329| 
FOGLI, B. F. C. dos S. A dialética da inclusão em educação: uma possibilidade em um cenário de contradições - um estudo de caso sobre a implementação da política de inclusão para alunos com deficiência na rede de ensino FAETEC. 2010. Tese (Doutorado em Educação) - Universidade do Estado do Rio de Janeiro, Rio de Janeiro, 2010.

FONTES, R. de S. O desafio da Educação Inclusiva no município de Niterói: das propostas oficiais às experiências em sala de aula. $160 \mathrm{f}$. Tese (Doutorado em Educação) Universidade do Estado do Rio de Janeiro, Rio de Janeiro, 2007.

GLAT, R. Educação Inclusiva na Rede Municipal de Educação do Rio de Janeiro: estudo etnográfico do cotidiano escolar e desenvolvimento de estratégias pedagógicas de ensinoaprendizagem para alunos com necessidades educacionais especiais em classes regulares. Relatório Científico entregue para a Secretaria Municipal de Educação do Rio de Janeiro, Rio de Janeiro, 2008.

GOYOS, A. C. N. A profissionalização de deficientes mentais: estudo da verbalização de professores acerca dessa questão. São Carlos: Editora da Universidade Federal de São Carlos, 1995, 117p.

IBGE. Instituto Brasileiro de Geografia e Estatística. Censo Demográfico 2010. Disponível em: <http://censo2010.ibge.gov.br/>. Acesso em 28 fev. 2013.

JODELET, D. Os processos psicossociais da exclusão. In: SAWAIA, B. (Org.). As artimanhas da exclusão: análise psicossocial e ética da desigualdade social. Petrópolis: Vozes, 2008.

LANCILLOTTI, S. S. P. Deficiência e trabalho: redimensionando o singular no contexto universal. Campinas-SP: Autores Associados, 2003.

MANZINI, E. J. Profissionalização de indivíduos portadores de deficiência mental: visão do agente institucional e visão do egresso. Dissertação (Mestrado em Educação Especial) Universidade Federal de São Carlos, São Carlos, 1989.

.; TANAKA, E. D. O. O que os empregadores pensam sobre o trabalho da pessoa com deficiência. Revista Brasileira de Educação Especial, Marília, v. 11, n. 2, p. 273-294, mai./ago. 2005.

MARTINS, J. de S. Exclusão Social e a nova desigualdade. São Paulo: Paulus, 1997.

MASCARO, C. A. A. de C. Capacitação de pessoas com deficiência intelectual para o trabalho: estudo de caso de um curso de capacitação profissional. Dissertação (Mestrado em Educação) - Universidade do Estado do Rio de Janeiro, Rio de Janeiro, 2012.

MATTOS, C. L. G. Imagens da Exclusão. Projeto de pesquisa. Rio de Janeiro: Uerj, 2002. 
MENDONÇA, R. C. T. Breves comentários sobre os dispositivos legais que subsidiam a política de inclusão das pessoas com deficiência no mercado de trabalho. 2007.

Disponível em: <http://saci.org.br/?modulo=akemi\&parametro=19683>. Acesso em: 28 fev. 2013.

NERI, M.; CARVALHO, A. P.; COSTILLA, H. G. Políticas de cotas e inclusão trabalhista de pessoas com deficiência. Ensaios Econômicos da EPGE/FGV, Rio de Janeiro, v. 462, 2002. Disponível em: <http://www.epge.fgv.br/portal/arquivo/1310.pdf>. Acesso em: 01 mar. 2013.

NETTO, J. M. F. Sexualidade e trabalho. In: OLIVEIRA, M. H. A. (Org.). Trabalho e deficiência mental: perspectivas atuais. Brasília-DF: Dupligráfica Ed., 2003. p. 93-110.

NUNES, L. R. O et al. Pesquisa em Educação Especial na Pós-graduação. Rio de Janeiro: Sette Letras, 1998.

OMOTE, S. Mudança de Atitudes Sociais em Relação à Inclusão. 2005. Disponível em: <http://www.sites.ffclrp.usp.br/paideia/artigos/32/07.htm>. Acesso em: 25 fev. 2013.

PEROSA, G. B. Colocação de deficientes mentais no mercado de trabalho: análise desta opção e treinamento de deficientes treináveis na função de empacotador de supermercado. Dissertação (Mestrado em Psicologia da Educação) - Pontifícia Universidade Católica de São Paulo, São Paulo, 1979.

PLETSCH, M. D. Repensando a Inclusão escolar de pessoas com deficiência mental: diretrizes políticas, currículo e práticas pedagógicas. Tese (Doutorado em Educação) Universidade do Estado do Rio de Janeiro, Rio de Janeiro, 2009.

REDIG, A. G. Ressignificando a Educação Especial no contexto da Educação Inclusiva: a visão de professores especialistas. Dissertação (Mestrado em Educação) - Universidade do Estado do Rio de Janeiro, Rio de Janeiro, 2010.

ROCHA, L. V. et al. Formação docente para suporte à inclusão social de jovens e adultos com deficiência intelectual. 2011. Disponível em:

<http://www.uel.br/eventos/congressomultidisciplinar/pages/arquivos/anais/2011/FORMACA O/199-2011.pdf>. Acesso em: 18 dez. 2013.

SAINT-JEAN, M. Organização do trabalho e saúde mental. Revista Terapia Ocupacional, São Paulo, v. 14, n. 3, p. 48-51, 2003.

SILVA, A. G. da. Profissionalização e mercado de trabalho para pessoas com deficiência mental no Brasil: o embuste neoliberal. Revista da Faculdade de Educação da UFG, v. 31, n. 2, p. 231-259, jul./dez., 2006.

TANAKA, E. D. O. Preparação profissional e social do portador de deficiência mental para o mercado de trabalho: comparação entre dois estudos. 1996. Dissertação (Mestrado em Educação) - Universidade Estadual de Londrina, Londrina, 1996.

|Fed. Nac. das Apaes - Fenapaes $\mid$ Brasília/DF | v.1 | nº | P. 53 - 69 |ago/dez .2013|ISSN 2237-4329| 


\section{Apøe Ciênciø Artigo}

TOLDRÁ, R. C.; DE MARQUE, C. B.; BRUNELLO, M. I. B. Desafios para a inclusão no mercado de trabalho de pessoas com deficiência intelectual: experiências em construção. Revista Terapia Ocupacional, São Paulo, v. 21, n. 2, p. 158-165, mai./ago. 2010.

UNESCO. Declaração de Salamanca e linha de ação sobre necessidades educativas especiais. Brasília: CORDE, 1994.

Declaração Mundial sobre Educação para Todos: satisfação das necessidades básicas de aprendizagem. Jomtien, 1990.

WANDERLEY, M. B. Refletindo sobre a noção de exclusão. In: SAWAIA, B. (Org.). As artimanhas da exclusão: análise psicossocial e ética da desigualdade social. Petrópolis: Vozes, 2008. 